$5-1-2017$

\title{
Quality of life in individuals surgically treated for congenital hydrocephalus during infancy: A single-institution experience
}

\author{
Saad Akhtar Khan \\ Aga Khan University, saad.akhtar@aku.edu \\ Muhammad Faheem Khan \\ Aga Khan University, muhammad.faheem@aku.edu \\ Saqib Kamran Bakhshi \\ Aga Khan University, saqib.bakhshi@aku.edu \\ Omar Irfan \\ Aga Khan University \\ Hamza Abdur Rahim Khan \\ Aga Khan University
}

See next page for additional authors

Follow this and additional works at: https://ecommons.aku.edu/pakistan_fhs_mc_surg_neurosurg

Part of the Neurology Commons, Neurosurgery Commons, and the Surgery Commons

\section{Recommended Citation}

Khan, S. A., Khan, M. F., Bakhshi, S. K., Irfan, O., Khan, H. A., Abbas, A., Awan, S., Bari, M. (2017). Quality of life in individuals surgically treated for congenital hydrocephalus during infancy: A single-institution experience. World Neurosurgery, 101, 247-253.

Available at: https://ecommons.aku.edu/pakistan_fhs_mc_surg_neurosurg/140 


\section{Authors}

Saad Akhtar Khan, Muhammad Faheem Khan, Saqib Kamran Bakhshi, Omar Irfan, Hamza Abdur Rahim Khan, Asad Abbas, Safia Awan, and Muhammad Ehsan Bari 


\title{
Quality of Life in Individuals Surgically Treated for Congenital Hydrocephalus During Infancy: A Single-Institution Experience
}

\author{
Saad Akhtar Khan 1,2, Muhammad Faheem Khan'2, Saqib Kamran Bakhshi', Omar Irfan ${ }^{4}$, Hamza Abdur Rahim Khan ${ }^{4}$, \\ Asad Abbas', Safia Awan', Muhammad Ehsan Bari²
}

BACKGROUND: Congenital hydrocephalus (CH) is a frequently encountered birth anomaly that can hinder longterm neurologic maturity and social well-being of affected children. This study was undertaken to assess quality of life (00L) 10-15 years after surgical treatment for primary CH during infancy at a tertiary care hospital in a developing country.

METHODS: This retrospective cohort study included individuals who presented to Aga Khan University Hospital, Karachi, Pakistan, between 1995 and 2005 at $<1$ year old and underwent surgery for primary $\mathrm{CH}$. The Hydrocephalus Outcome Questionnaire was used to assess outcomes with respect to $\mathrm{QOL}$.

RESULTS: Of 118 patients, 90 patients participated in the study. Mean age at first admission was 6.2 months. Mean length of follow-up was 5.4 years. Of these, 28 patients had died after surgery. Shunt infection $(P=0.012)$ and delayed milestones $(P=0.003)$ were found to be statistically significant factors affecting mortality in the patients who died. The mean overall health score was $\mathbf{0 . 6 7} \pm \mathbf{0 . 3 0}$. Age $<6$ months at the time of first surgery was a poor predictor of overall health on the Hydrocephalus Outcome Questionnaire $(P=0.039)$.

CONCLUSIONS: In our analysis, we assessed the 0OL associated with $\mathrm{CH}$. We hope that these results will provide insight for future prospective work with the ultimate goal of improving long-term $\mathbf{0 O L}$ in children with $\mathrm{CH}$.

\section{INTRODUCTION}

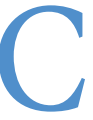
ongenital hydrocephalus $(\mathrm{CH})$ is a common birth disorder. ${ }^{\mathrm{I}}$ Increased intracranial pressure in affected children makes them prone to future seizure disorders, cognitive decline, and mental retardation. ${ }^{2,3}$ A previous study reported that approximately one third of patients with $\mathrm{CH}$ had seizure disorders, and approximately $40 \%$ had an IQ of $<70 .^{2,3}$ Lindquist et al. ${ }^{4}$ reported considerable difficulty in cognition even in children with hydrocephalus who had a normal or a near-normal IQ.

Quality of life (QOL) reflects a subjective assessment of emotional, cognitive, and physical health and social well-being in individuals. ${ }^{5}$ The perceived impact of a health-impairing condition on $\mathrm{QOL}$ is different depending on whether the disease is congenital, acquired early in life, or develops at a later stage. ${ }^{4}$ Kulkarni et al., ${ }^{6}$ using a self-designed questionnaire, the Hydrocephalus Outcome Questionnaire ( $\mathrm{HOQ})$, reported that parents perceived frequent seizures and shunt-related complications as some of the predictors of poor QOL in children with $\mathrm{CH}$. Gupta et al. ${ }^{7}$ studied patients $>20$ years old who had had early-onset hydrocephalus and reported depression in more than two thirds of them.

Pakistan is a developing country with an estimated population of Igr million, a per capita gross domestic product of approximately $6 \%$ of the world's average, and an average literacy rate of approximately $55 \%$. $\mathrm{CH}$ is the most common neurologic congenital defect in Pakistan, and most children with $\mathrm{CH}$ are treated surgically. ${ }^{8,9}$ However, $\mathrm{CH}$ involves long-term follow-up and is associated with numerous possible complications. Rashid et al. ${ }^{\text {IO }}$ reported a poor surgical outcome in children treated for pediatric hydrocephalus in Pakistan. Considering the prevalent poverty as well as the lack of well-developed social rehabilitation

\section{Key words}

- Congenital

- Hydrocephalus

- Hydrocephalus Outcome Questionnaire (HOO)

- Quality of life (OOL)

\section{Abbreviations and Acronyms}

$\mathrm{CH}$ : Congenital hydrocephalus

HOQ: Hydrocephalus Outcome Questionnaire

0.0L: Quality of life
From the ${ }^{1}$ Department of Neurosurgery, Memon Medical Institute Hospital, ${ }^{2}$ Section of Neurosurgery, Department of Surgery, ${ }^{3}$ Department of Medicine, and ${ }^{4}$ Medical College, Aga Khan University Hospital, Karachi, Pakistan

To whom correspondence should be addressed: Muhammad Ehsan Bari [E-mail: ehsan.bari@aku.edu]

$\triangle$ Supplementary digital content available online.

Citation: World Neurosurg. (2017) 101:247-253

http://dx.doi.org/10.1016/j.wneu.2017.01.107

Journal homepage: www.WORLDNEUROSURGERY.org

Available online: www.sciencedirect.com

1878-8750/\$ - see front matter @ 2017 Elsevier Inc. All rights reserved. 
programs in Pakistan, evaluation of QOL in patients treated for $\mathrm{CH}$ requires the identification, survey, and analysis of such patients in our health care system.

The purpose of this study is to examine the management and prognosis of patients treated for $\mathrm{CH}$ in a resource-limited setting such as ours. Up to this time, there have been no data available from Pakistan to investigate and address QOL in patients who
Quite a bit true: 3

Very true: 4

The scores of the items are summed and then divided by the highest possible summed score to provide a final score on a 0.0 to I.o metric.

\section{Physical Health score $=\left(\sum[\right.$ scores of items I -15$\left.]\right) \div 60$ \\ Social - Emotional Health score $=\left(\sum\right.$ [scores of items I6 - 39] $) \div 96$ \\ Cognitive Health score $=\left(\sum\right.$ [scores of items $\left.\left.40-5 \mathrm{I}\right]\right) \div 48$ \\ Overall Health score $=\left(\sum[\right.$ scores of items $\left.\mathrm{I}-5 \mathrm{I}]\right) \div 204$}

survive after being treated for $\mathrm{CH}$ during their infancy. We believe this study will help highlight the social burden of this disease and increase its awareness at a national level, initiating analysis on a larger scale and ultimately leading to the establishment of more rehabilitation centers in Pakistan. Surgical intervention and longterm follow-up to prevent complications are not enough for the proper care of these patients. Accepting that premise, this study assessed the QOL of patients IO-I5 years after they were treated surgically for primary $\mathrm{CH}$ during their infancy at a tertiary care hospital in a developing country.

\section{MATERIALS AND METHODS}

Approval from the ethics board was obtained before this retrospective cohort study was initiated. All patients who had been treated surgically for primary $\mathrm{CH}$ during the period $1995-2005$ at Aga Khan University Hospital, Karachi, Pakistan, were included in the study. Of II8 patients identified, 9o fulfilled the inclusion criteria and were selected for this study. There were 28 patients excluded because of either incomplete or missing records $(n=8)$, being operated on in another hospital $(n=I I)$, or not giving consent to participate in the study $(n=9)$. Data were retrieved through patient files using International Classification of Diseases, 9th Revision, code 742.3. Patients who had hydrocephalus secondary to meningitis, tumor, or subarachnoid/intraventricular hemorrhage were excluded. The HOQ, a standardized 5I-item questionnaire employing the domains of physical, social-emotional, and cognitive health to measure QOL, was used with permission from Kulkarni, ${ }^{\mathrm{II}}$ who developed and tested this questionnaire.

\section{DATA COLLECTION}

We used Kulkarni's HOQ questionnaire, which has been tested for reliability and construct validity and has demonstrated excellent test-retest reliability (0.93, 95\% confidence interval, o.88-0.96), interrater reliability (o.88, 95\% confidence interval, $0.79-0.93$ ), and internal consistency (Cronbach's $\alpha$ 0.94). ${ }^{6}$ The response of each item is on a 5 -point scale, given a score from o to 4 . For all questions, the following values are entered manually for the various response options:

Not at all true: 0

A little true: I

Somewhat true: 2
Scores of 0.00 ("worse health status") and I.oo ("better health status") were used for HOQ score interpretation.

Information regarding patient demographics, clinical presentation, and complications of surgery was collected through review of medical records using another self-designed structured questionnaire. Complications were noted for the entire follow-up period. The HOQ was mostly completed by parents of patients and by patients themselves where applicable, with the assistance of a single dedicated neurosurgery resident with at least 2 years of experience. This was done to minimize bias and interobserver variability. Where required, phone calls were made to respondents for the completion of data. Almost all patients were followed through clinics and medical records. However, phone calls were made for the completion of data in some cases because of long distance constraints (e.g., a different city of residence). The data were collected after obtaining consent from the respondent, ensuring protection of the patient's identity and confidentiality during all stages.

\section{Statistical Analysis}

Data were analyzed using IBM SPSS Statistics for Windows, Version 2I.o (IBM Corp., Armonk, New York, USA). Continuous data were presented as means with SDs. Categorical data were presented as frequencies and proportions. Nonparametric tests including independent sample Mann-Whitney $U$ test and KruskalWallis test were used to compare continuous data. Several independent variables were tested for possible association with QOL, using the HOQ overall health score as the dependent variable. $P$ value of $<0.05$ was taken as significant. Univariate analysis was performed on all independent factors hypothesized to indirectly affect QOL parameters. Multivariate analysis using regression analysis of variance was performed on variables that showed statistically significant results on univariate analysis.

\section{RESULTS}

Of 90 patients who had undergone the insertion of a ventriculoperitoneal shunt, $40(44.4 \%)$ were male, and $50(55.6 \%)$ were female. Mean age of patients at first admission was 6.2 months; $70(77 \%)$ patients were operated on before 6 months of age. The mean length of hospital stay was 2I days. The mean follow-up time after the surgery was 5.4 years. Complications developed in $56(62.2 \%)$ patients who underwent surgery, whereas $34(37.8 \%)$ patients did not experience any complications. The 
most common complication observed was shunt blockage, encountered in $53.6 \%$ of patients, followed by septic complications (46.4\%) and seizures (2r.4\%) (Tables 1 and 2).

In our cohort, $28(3 \mathrm{I} \%)$ patients had died after surgery. Assessment of the causes of death showed that 14 (50\%) patients had died from septic complications, including 2 patients who had developed complicated meningitis and 6 patients who had progressive metabolic disease. Shunt blockage was the cause of death in $\mathrm{I} 2(42.8 \%)$ patients, including 8 patients who had died secondary to uncontrolled seizures at home with apparent cerebral hypoxic injury noted on computed tomography scan. In 2 patients, the cause of death remained uncertain.

Mortality was considered an event instead of a complication. Septic complications $(\mathrm{P}=$ o.or2 $)$ and delayed milestones $(\mathrm{P}=0.003)$ were statistically significant factors affecting mortality in these patients. Factors such as shunt blockage, seizures, age, and sex were not observed to be statistically significant factors affecting mortality.

Among the surviving 62 children, 48 (77.4\%) were school-age; $36(75 \%)$ of these children attended normal school and had completed or were still continuing their education, $4(8.3 \%)$ had left normal school before completion, and 8 (I6.7\%) attended special school. Delayed milestones were reported in $48.9 \%$ of children. Reoperations (either revision of shunt or insertion of a new shunt on the opposite side) were performed in $36(58.2 \%)$ patients; 30 children $<6$ months old required revision compared with 6 children $>6$ months old. Only 6 patients $(6.6 \%$; all $<6$ months old) required $>2$ reoperations. However, there was no significant association of age with the number of reoperations.

Parents of the surviving 62 children consented to complete the HOQ. The mean HOQ physical health score was $0.68 \pm 0.30$, mean social-emotional health score was $0.66 \pm 0.3 \mathrm{I}$, mean cognitive health score was $0.70 \pm 0.33$ and mean overall health score was $0.67 \pm 0.30$ (Figure 1). Age $<6$ months at the time of first surgery was a poor predictor of HOQ overall health $(\mathrm{P}=$ o.039). Poor HOQ cognitive health outcome was observed in patients who underwent reoperations $(\mathrm{P}=0.0 \mathrm{r})$ and patients who had delayed milestones $(\mathrm{P}=0.009)$. Delayed milestones $(P=0.025)$ also negatively affected HOQ social-emotional health (Tables 3 and 4).

\section{DISCUSSION}

In our analysis, we observed the rate of treatment complications and examined QOL associated with $\mathrm{CH}$. We used the validated HOQ, which was methodically designed and tested by Kulkarni et al. ${ }^{6}$ and allowed the independent verification of patient data. In our study, we were able to truly reflect on the QOL of children treated for $\mathrm{CH}$ in our health care system. Other available outcome measures, which are not disease-specific, include PedsQL, Health Utilities Index, and the Child Health Questionnaire. ${ }^{\text {I2-I4 }}$

Traditionally, the outcome parameters used to measure treatment success in hydrocephalus mostly revolved around minimizing surgical complications. ${ }^{15}$ However, it is now understood that the term "successful treatment" involves outcome measures pivoting around QOL and not merely surgical success. Jones and Klinge $^{\mathrm{I} 6}$ emphasized that QOL is regarded as the most important outcome in patients with hydrocephalus. QOL is a
Table 1. Congenital Hydrocephalus Characteristics in 90

Patients

Variable

Number of Patients (\%)

Sex

\begin{tabular}{ll} 
Male & $40(44.4)$ \\
\hline
\end{tabular}

Age at first operation

$<6$ months $\quad 70(77.8)$

$>6$ months $\quad 20$ (22.2)

Complications

Yes $\quad 56$ (62.2)

No 34 (37.8)

Type of complications

\begin{tabular}{ll} 
Shunt blockage & $30(53.6)$ \\
\hline Septic complication & $32(57.1)$ \\
\hline Seizures & $12(21.4)$ \\
\hline
\end{tabular}

Mortality 28 (31)

Septic complication $14(50)$

Shunt blockage 12 (42.9)

Unknown 2 (7.1)

School age $\quad 48(77.4)$

Normal school $\quad 36$

Special school $\quad 8$

Dropped out 4

Delayed milestones $\quad 44(48.9 \%)$

Reoperations $\quad 36(58.2 \%)$

Age $<6$ months $\quad 30$

Age $>6$ months 6

Table 2. Patient Characteristics (Continuous Variables)

\begin{tabular}{|l|c|c|}
\hline Variable & Mean \pm SD & Range \\
\hline Current age, years & $11 \pm 2.9$ & $5-18$ \\
\hline Age at first operation, months & $6.2 \pm 9.9$ & $0-50$ \\
\hline Length of hospital stay, days & $21.1 \pm 17.3$ & $3-65$ \\
\hline Follow-up after surgery, years & $5.4 \pm 4.4$ & $0-14$ \\
\hline Number of reoperations & $0.53 \pm 0.89$ & $0-5$ \\
\hline HOO physical & $0.68 \pm 0.30$ & $0.10-1.0$ \\
\hline HOO social-emotional & $0.66 \pm 0.31$ & $0.00-1.0$ \\
\hline HOO cognitive & $0.70 \pm 0.33$ & $0.00-1.0$ \\
\hline HOO overall & $0.67 \pm 0.30$ & $0.02-1.0$ \\
\hline H0O, Hydrocephalus Outcome Questionnaire. & & \\
\hline
\end{tabular}




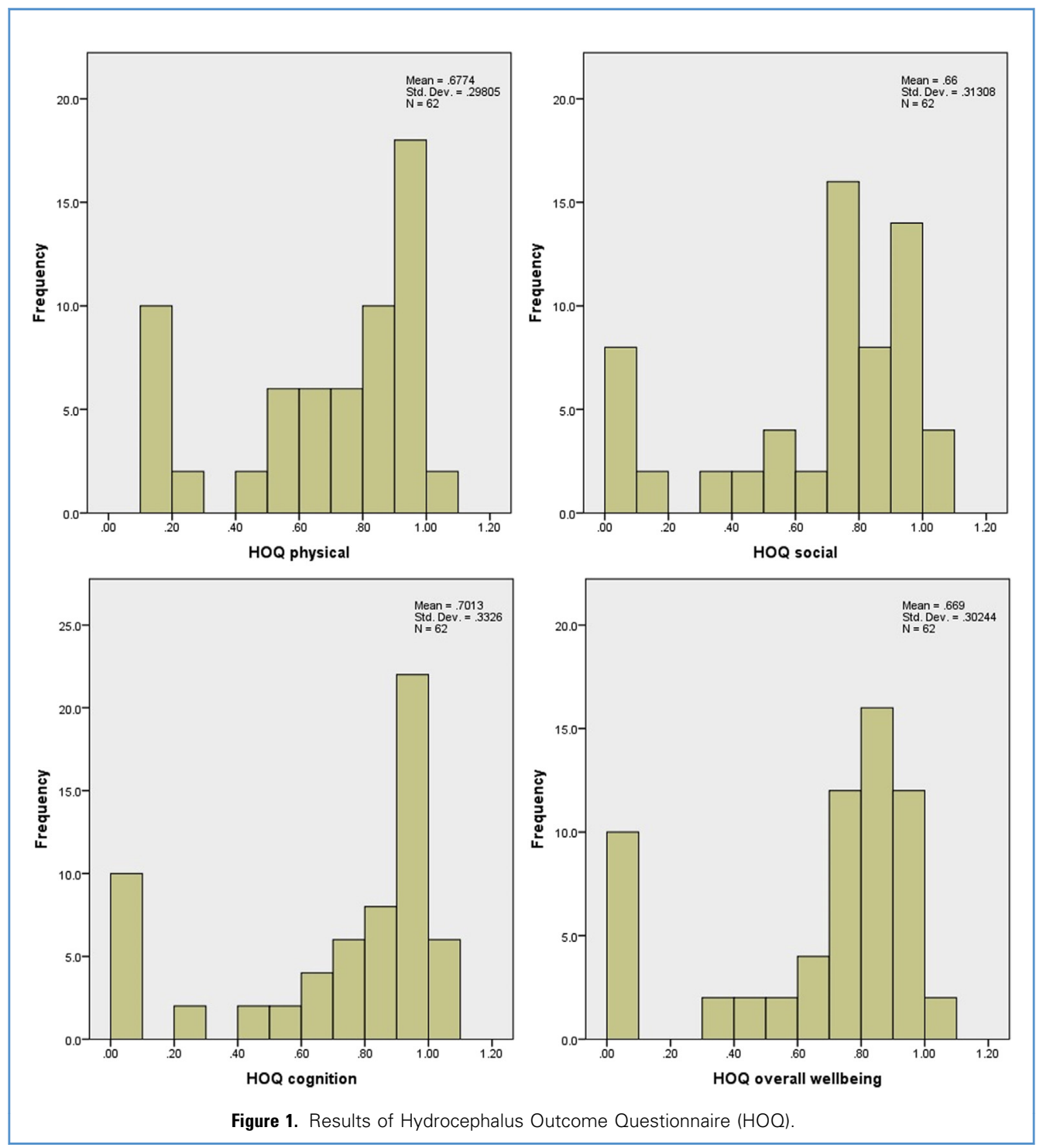

broad multidimensional concept that is similar to the World Health Organization concept of health as "a state of complete physical, mental, and social well-being and not merely the absence of disease or infirmity." 5 "Health" or "QOL" is not only about physical aspects but also includes cognitive, emotional, and social aspects.

The literature regarding QOL outcomes for children with $\mathrm{CH}$ is evolving. It might help to identify patients at risk for a negative outcome, thus ultimately aiding in directing health care and social resources in a more outcome-specific way. We believe that this approach would help especially in resource-challenged health care systems and developing countries such as Pakistan, where $\mathrm{CH}$ is the most common neurologic congenital defect and also the most common reason for neurosurgical intervention in pediatric patients. ${ }^{9, \text { Io }}$ These children, after surgery and initial screening for possible complications, are critically exposed to economic and social handicaps due to a lack of awareness programs and good social rehabilitation centers, increasing the probability of suboptimal health outcomes and QOL.

\section{Septic Complications}

In the present study, we tried to quantify septic complications and their severity through indirect correlation with the total accumulated stay in the hospital (i.e., the sum of all admissions over the child's lifetime up to this study). We believe that this information helps in quantifying the difficulty in treating the infection. It is a common hypothesis that intracranial infections have devastating effects on a child's developing brain. However, we concluded that patients who had septic complications required prolonged treatment but fared worse only in the HOQ social-emotional health outcome. Septic complications had no effect on physical, cognitive, or overall health outcome. Furthermore, we could not establish any meaningful connection between increased accumulated stay for treatment of septic complications during a child's 
Table 3. Univariate Analysis of Predictors of Hydrocephalus Outcome Questionnaire Health Scores (P Values)

\begin{tabular}{|c|c|c|c|c|}
\hline Variable & $\begin{array}{c}\text { HOO Physical Health } \\
\text { Outcome }\end{array}$ & $\begin{array}{l}\text { HOO Social and Emotional } \\
\text { Health Outcome }\end{array}$ & $\begin{array}{l}\text { HOO Cognitive Health } \\
\text { Outcome }\end{array}$ & $\begin{array}{l}\text { HOO Overall Health } \\
\text { Outcome }\end{array}$ \\
\hline Age & $<0.001$ & $<0.001$ & $<0.001$ & $<0.001$ \\
\hline Sex & 0.95 & 0.98 & 0.65 & 0.81 \\
\hline Length of hospital stay & 0.17 & 0.36 & 0.32 & 0.24 \\
\hline Seizures & 0.16 & 0.28 & 0.27 & 0.22 \\
\hline Septic complication & 0.04 & 0.07 & 0.01 & 0.04 \\
\hline Shunt blockage & 0.37 & 0.34 & 0.45 & 0.40 \\
\hline Delayed milestones & 0.67 & 0.01 & 0.03 & 0.07 \\
\hline Reoperations & 0.79 & 0.22 & $<0.001$ & 0.32 \\
\hline
\end{tabular}

lifetime and overall outcome. Previous studies have indicated that septic complications such as shunt infection pose a grave challenge for children with $\mathrm{CH}$, with an estimated incidence of $3 \%-$ $20 \%{ }^{17-\mathrm{I} 9}$ In addition, it is postulated that in $3 \%$ of operations for shunt insertion, the cerebrospinal fluid is already infected. Contrary to our results, many authors have suggested that the presence of shunt infection is associated with a worse outcome in children with hydrocephalus. ${ }^{20,21}$

\section{Seizures}

In the present study, we were unable to find any statistically significant relationship between the presence of seizures and the worsening of HOQ overall health outcome $(\mathrm{P}=0.07 \mathrm{I})$. However, the current literature strongly suggests an intimate association between the presence of seizures and poorer outcomes. ${ }^{22-25}$ Although much debate exists to date whether the presence of seizures is a marker of more morbid brain disease and hence worse outcomes or whether the seizure frequency directly impacts neurologic function, affecting the outcome, Kulkarni and Shams ${ }^{22}$ were the first to suggest that not only the presence of epilepsy but also the frequency of seizures significantly impacts QOL. They reported that patients with multiple daily seizures had an HOQ overall health score 0.32 lower than patients who had no seizures. $^{22}$ In a further subcategorization, children having a single episode of seizure per day had worse outcomes than children with no seizures, whereas children with multiple daily seizures fared the worst. ${ }^{22}$

Table 4. Multivariate Analysis of Significant Predictors of Hydrocephalus Outcome Questionnaire Health Scores (PValues)

\begin{tabular}{|l|c|c|c|}
\hline Variable & Overall & Cognitive & Social-Emotional \\
\hline Age $<6$ months & 0.039 & 0.167 & 0.061 \\
\hline Reoperations & 0.326 & 0.012 & 0.220 \\
\hline Delayed milestones & 0.060 & 0.009 & 0.025 \\
\hline
\end{tabular}

\section{Mortality}

We observed 28 (31\%) deaths, I4 (50\%) of which were due to septic complications and $12(43 \%)$ were due to shunt blockage. In their 20-year follow-up report of ${ }_{13} 8$ patients, Paulsen et al. ${ }^{26}$ observed $30(22 \%)$ cases of mortality, most of which were due to tumor-related causes or severe congenital malformations. They reported a $13 \%$ mortality rate when observing non-tumorrelated causes. Other long-term studies on Io-year mortality rates in individuals with shunts reported similar rates of $\mathrm{II} \%-\mathrm{I} 4 \% .^{27-29}$ Shunt-related deaths in hydrocephalus studies have reported rates of $2 \%-5 \%,{ }^{23,27,30}$ with Paulsen et al. reporting a rate of $2.9 \%$. $^{26}$ Paulsen et al. ${ }^{26}$ emphasized that this was due to not recognizing a blocked shunt and dealing with it promptly. Providing guidelines to the patients, family, and caregivers on detecting shunt failure along with increased surveillance scans could contribute to earlier detection and prevention of mortality related to shunt failure. In our study, we believe that a high mortality rate mainly related to shunt complications is associated with a low socioeconomic background of the population coupled with the unavailability of resources and a poor referral system.

Septic complications $(\mathrm{P}=0 . \mathrm{or} 2)$ and delayed milestones $(\mathrm{P}=$ $0.003)$ were analyzed to be statistically significant factors affecting mortality in our patients. Of the 28 patients who died, $20(7 \mathrm{I} \%)$ were $<6$ months old, implying a higher mortality at a younger age of procedure, although this was not statistically significant. In our study, $77.8 \%$ of the children who were $<6$ months old required a total of 42 shunt revisions, but the difference compared with other age groups was not significant. In the study by Paulsen et al., ${ }^{26}$ $49 \%$ of patients $<6$ months old required 304 revisions. There was a significant difference in number of shunt revisions for this age group compared with the other patient age groups in their study.

\section{HOO Social-Emotional Score}

Although the distribution of HOQ scores showed variations in our study, the mean social-emotional score of $0.66 \pm 0.3 \mathrm{I}$ was notably lower than the mean physical score or mean cognitive score. Our mean social-emotional score was also lower than the mean 
social-emotional score of $0.72 \pm 0.18$ observed by Kulkarni and Shams. ${ }^{22}$ As our results reflect a single institution, even this may be understating the possibility of this burden. Furthermore, delayed milestones $(P=0.025)$ negatively affected this outcome.

\section{HOQ Cognitive Score}

Our study reported a mean HOQ cognitive score that was notably higher $(0.70 \pm 0.33)$ than the mean physical score or socialemotional score. This was contrary to what authors of previously conducted studies have extensively demonstrated with respect to cognitive difficulties encountered by children with hydrocephalus. Kulkarni and Shams ${ }^{22}$ reported a cognitive health score of $0.57 \pm$ 0.27 , which was the lowest score compared with all other outcome measures in their cohort. Similarly, Hoppe-Hirsch et al. ${ }^{23}$ reported an IQ of $<70$ in $40 \%$ of patients with hydrocephalus. Lindquist et al. $^{3}$ reported an IQ of $<70$ in $37 \%$ of patients in an epidemiologic study focused on learning disabilities in patients affected with hydrocephalus. Other authors have revealed difficulties with narration and oral and reading comprehension. ${ }^{3 \mathrm{I}}$ Although it is difficult to ascertain with confidence the reason for the favorable outcome in cognitive health in our study, it may be attributed to a tight-knit joint family environment. In our study, a poor HOQ cognitive health outcome was observed in patients who underwent reoperations $(\mathrm{P}=0.012)$ and patients who had delayed milestones $(\mathrm{P}=0.009)$.

\section{HOQ Overall Health Score}

Our HOQ overall health score $(0.67 \pm 0.30)$ is similar to that reported by Kulkarni and Shams (0.68 \pm o.19). ${ }^{22}$ Moreover, we observed that age $<6$ months at the time of first operation was associated with a worse overall health outcome $(\mathrm{P}=0.039)$. Furthermore, seizures, length of stay, and reoperations did not significantly affect overall outcome in our study as was reported by Kulkarni and Shams.

\section{Reoperations}

In our cohort, the need for reoperations in treatment of hydrocephalus pointed toward the complexity of the condition, whether attributed to catheter blockage, a loculated cerebrospinal fluid system, or in cases in which concurrent endoscopy was attempted.
However, the presence of reoperations did not negatively impact the HOQ overall health outcome $(P=0.326)$. Our result was contradictory to the analysis of Kulkarni and Shams, ${ }^{22}$ who observed that the number of reoperations correlated as an independent predictor to negatively affect the HOQ overall health outcome. Although Kulkarni and Shams ${ }^{22}$ further commented on the ambiguity of the mechanism by which catheter load impacts outcome, it can be assumed that the need for reoperation is an indirect marker of complicated hydrocephalus that is associated with a worse outcome.

\section{Limitations}

Being a retrospective study, our report has all the limitations inherent to that design. In addition, our study was a single-center analysis with a relatively small sample size. Moreover, the participation rate in this study was not very high $(76 \%)$; this was particularly due to a high rate of nonconsent. We did not include data on patients who had missing records; therefore, we are unsure how this would have affected our results. Furthermore, we interviewed by telephone some patients who were living at a far distance, and this might have introduced a recall bias.

\section{CONCLUSIONS}

Our analysis of $\mathrm{CH}$ allowed us to observe for the first time some interesting patterns, associations, and the rate of treatment complications in our health care system as well as assess QOL. We believe that the most important areas of focus are the prevention of seizures, shunt infections, and reoperations along with social rehabilitation of these children. It is hoped that future research incorporating several socioeconomic variables will improve our understanding of all the complex interactions that ultimately determine a child's outcome. Our results will provide insight for future work and will generate a better perception at a national level about children with $\mathrm{CH}$, with the ultimate goal of improving their long-term QOL.

\section{ACKNOWLEDGMENTS}

We thank Maryam Sarfraz for her support in manuscript preparation.

\section{REFERENCES}

I. Kutscher A, Nestler U, Bernhard MK, Merkenschlager A, Thome U, Kiess W, et al. Adult long-term health-related quality of life of congenital hydrocephalus patients. J Neurosurg Pediatr. 2015;16:62I-625.

2. Persson EK, Hagberg G, Uvebrant P. Hydrocephalus prevalence and outcome in a populationbased cohort of children born in I989-1998. Acta Paediatr. 2005;94:726-732.

3. Lindquist B, Carlsson G, Persson EK, Uvebrant P. Learning disabilities in a population-based group of children with hydrocephalus. Acta Paediatr. 2005;94:878-883.

4. Lindquist B, Fernell E, Persson E-K, Uvebrant P. Quality of life in adults treated in infancy for hydrocephalus. Childs Nerv Syst. 20I4;30:I4I3-I4I8.
5. World Health Organization. Health promotion: a discussion document on the concept and principles: summary report of the Working Group on Concept and Principles of Health Promotion, Copenhagen, July 9-I3, I984, WHO Regional Office for Europe; Copenhagen; http://apps.who. int/iris/handle/10665/107835.

6. Kulkarni AV, Rabin D, Drake JM. An instrument to measure the health status in children with hydrocephalus: the Hydrocephalus Outcome Questionnaire. J Neurosurg Pediatr. 2004;IOI:I34-I40.

7. Gupta N, Park J, Solomon C, Kranz DA, Wrensch M, Wu YW. Long-term outcomes in patients with treated childhood hydrocephalus. J Neurosurg Pediatr. 2007;106:334-339.

8. Perveen F, Tyyab S. Frequency and pattern of distribution of congenital anomalies in the newborn and associated maternal risk factors. J Coll Physicians Surg Pak. 2007;17:340-343.

9. Rehman A, Fatima S, Soomro N. Frequency of congenital anomalies and associated maternal risk factors in the lower socio-economic group. Pak J Surg. 2006;22:I69-I73.

Io. Rashid QT, Salat MS, Enam K, Kazim SF Godil SS, Enam SA, et al. Time trends and agerelated etiologies of pediatric hydrocephalus: results of a groupwise analysis in a clinical cohort. Childs Nerv Syst. 20I2;28:22I-227.

II. Kulkarni AV. An instrument to measure the health status of children with hydrocephalus: the Hydrocephalus Outcome Questionnaire. Cerebrospinal Fluid Res. 2005;2:I.

I2. Furlong WJ, Feeny DH, Torrance GW, Barr RD The Health Utilities Index (HUI) system for 
assessing health-related quality of life in clinical studies. Ann Med. 2001;33:375-384.

I3. Raat H, Botterweck AM, Landgraf JM, Hoogeveen WC, Essink-Bot M-L. Reliability and validity of the Short Form of the Child Health Questionnaire for Parents (CHQ- $\left.\mathrm{PF}_{2} 8\right)$ in large random school based and general population samples. J Epidemiol Community Health. 2005;59:75-82.

I4. Varni JW, Seid M, Rode CA. The PedsQL: measurement model for the pediatric quality of life inventory. Med Care. I999;37:126-I39.

I5. Drake JM, Canadian Pediatric Neurosurgery Study Group. Endoscopic third ventriculostomy in pediatric patients: the Canadian experience. Neurosurgery. 2007;60:88I-886

I6. Jones HC, Klinge PM. Hydrocephalus 2008, I7-2oth September, Hannover Germany: a conference report. Cerebrospinal Fluid Res. 2008;5:I9.

I7. Kulkarni AV, Drake JM, Lamberti-Pasculli M. Cerebrospinal fluid shunt infection: a prospective study of risk factors. J Neurosurg. 200I;94:I95-20I.

I8. Wong JM, Ziewacz JE, Ho AL, Panchmatia JR, Bader AM, Garton HJ, et al. Patterns in neurosurgical adverse events: cerebrospinal fluid shunt surgery. Neurosurg Focus. 2012;33:EI3.

I9. Ammirati M, Raimondi AJ. Cerebrospinal fluid shunt infections in children. Childs Nerv Syst. I987; 3:I06-I09.

20. McGirt MJ, Leveque J-C, Wellons JC III, Villavicencio AT, Hopkins JS, Fuchs HE, et al. Cerebrospinal fluid shunt survival and etiology of failures: a seven-year institutional experience. Pediatr Neurosurg. 2002;36:248-255.

2I. Vinchon M, Dhellemmes P. Cerebrospinal fluid shunt infection: risk factors and long-term followup. Childs Nerv Syst. 2006;22:692-697.

22. Kulkarni AV, Shams I. Quality of life in children with hydrocephalus: results from the Hospital for Sick Children, Toronto. J Neurosurg. 2007; IO7(5 suppl):358-364.

23. Hoppe-Hirsch E, Laroussinie F, Brunet L, Sainte Rose C, Renier D, Cinalli G, et al. Late outcome of the surgical treatment of hydrocephalus. Childs Nerv Syst. I998;14:97-99.

24. Heinsbergen I, Rotteveel J, Roeleveld N, Grotenhuis A. Outcome in shunted hydrocephalic children. Eur J Paediatr Neurol. 2002;6:99-I07.

25. Vinchon M, Rekate H, Kulkarni AV. Pediatric hydrocephalus outcomes: a review. Fluids Barriers CNS. 20I2;9:I.

26. Paulsen AH, Lundar T, Lindegaard K-F. Twentyyear outcome in young adults with childhood hydrocephalus: assessment of surgical outcome, work participation, and health-related quality of life: clinical article. J Neurosurg Pediatr. 20Io;6: 527-535.

27. Casey AT, Kimmings EJ, Kleinlugtebeld AD, Taylor WA, Harkness WF, Hayward RD. The longterm outlook for hydrocephalus in childhood. A ten-year cohort study of 155 patients. Pediatr Neurosurg. I997;27:63-70.
28. Lumenta CB, Skotarczak U. Long-term follow-up in 233 patients with congenital hydrocephalus. Childs Nerv Syst. I995;II:I73-175.

29. Tuli S, Tuli J, Drake J, Spears J. Predictors of death in pediatric patients requiring cerebrospinal fluid shunts. J Neurosurg. 2004;100(5 Suppl Pediatrics): 442-446.

30. Jansen J, Jørgensen M. Prognostic significance of signs and symptoms in hydrocephalus. Analysis of survival. Acta Neurol Scand. I986;73:55-65.

3I. Dennis M, Barnes M, Hetherington CR. Congen ital hydrocephalus as a model of neurodevelopmental disorder. In: Tager-Flusberg H, ed. Neurodevelopmental Disorders: Contribution to a New Perspective from the Cognitive Neurosciences. Cambridge, MA: MIT Press; I999:505-532.

Conflict of interest statement: The authors declare that the article content was composed in the absence of any commercial or financial relationships that could be construed as a potential conflict of interest.

Received 26 December 2016; accepted 26 January 2017 Citation: World Neurosurg. (2017) 101:247-253. http://dx.doi.org/10.1016/j.wneu.2017.01.107 Journal homepage: www.WORLDNEUROSURGERY.org Available online: www.sciencedirect.com 1878-8750/\$ - see front matter (c) 2017 Elsevier Inc. All rights reserved.

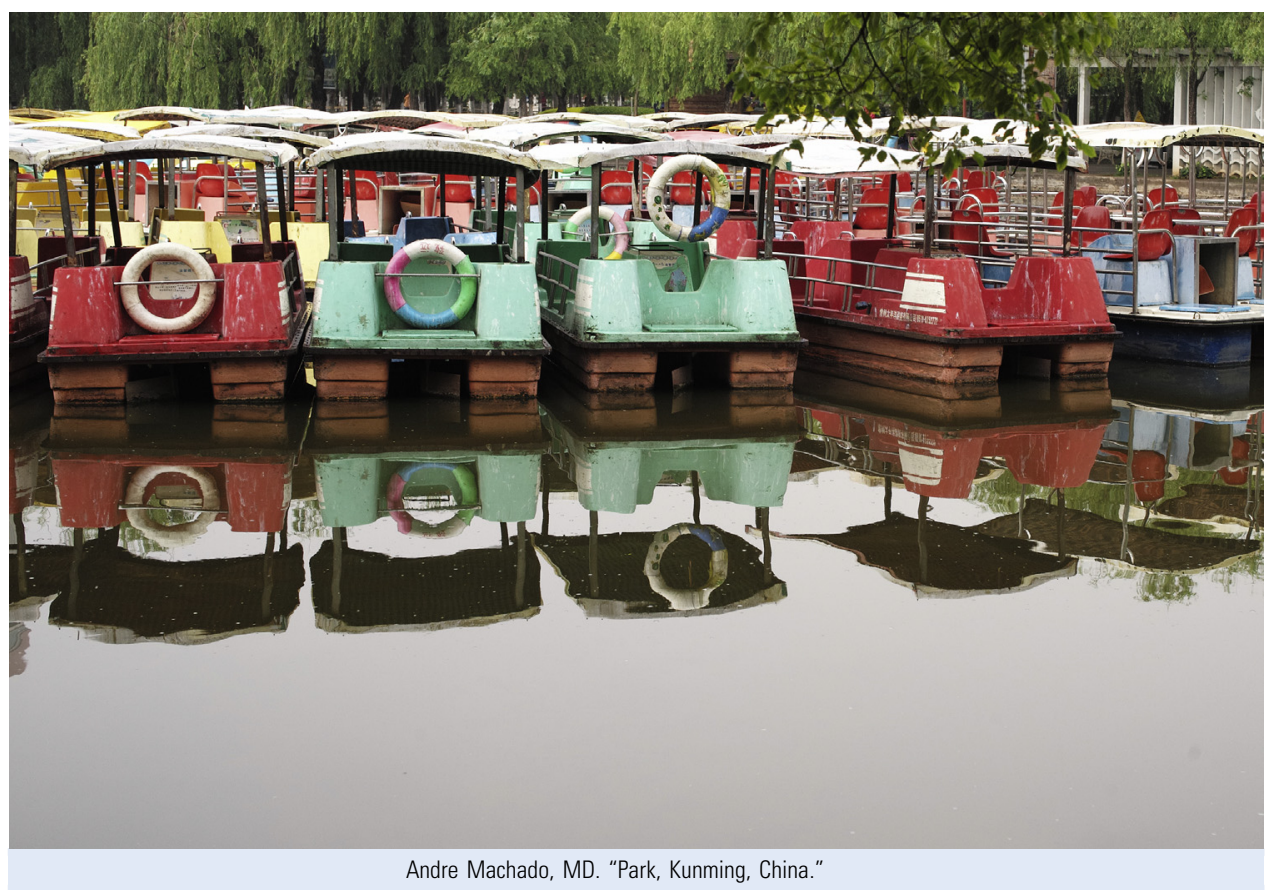

